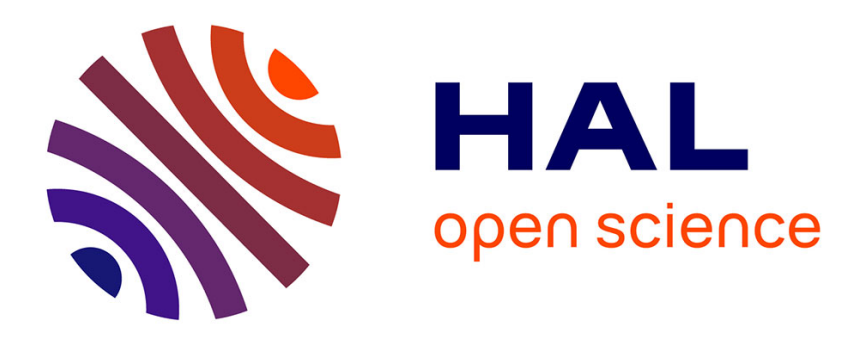

\title{
A model of distance analysis. Epistemic field notes for education ethnographers
}

Olivier Marty

\section{To cite this version:}

Olivier Marty. A model of distance analysis. Epistemic field notes for education ethnographers. Ethnography and Education, 2014, vol. 10 ( $\mathrm{n}^{\circ}$ 1), pp. 17-27. 10.1080/17457823.2014.922892 . halshs01010283

\section{HAL Id: halshs-01010283 \\ https://shs.hal.science/halshs-01010283}

Submitted on 9 Jul 2014

HAL is a multi-disciplinary open access archive for the deposit and dissemination of scientific research documents, whether they are published or not. The documents may come from teaching and research institutions in France or abroad, or from public or private research centers.
L'archive ouverte pluridisciplinaire HAL, est destinée au dépôt et à la diffusion de documents scientifiques de niveau recherche, publiés ou non, émanant des établissements d'enseignement et de recherche français ou étrangers, des laboratoires publics ou privés. 


\title{
A model of distance analysis. Epistemic field notes for education ethnographers.
}

O. Marty*

\author{
CRF, Conservatoire National des Arts et Métiers, Paris, France
}

\begin{abstract}
This document aims to help education ethnographers to think about, describe and complete their scientific research: based on a personal research curricula and ongoing scientific discussions in social sciences and psychology, I develop an anthropology synthesis of three epistemic distances. (1) Cultural distance from fieldwork: How far is the education ethnographer from educational actors he/she is studying through a participatory observation? (2) Distance from scientific community: Once fully integrated within education fieldwork and into research action, how far is the education ethnographer from the scientific community of 'armchair anthropologists'? (3) Distance from oneself: how can an education ethnographer overcome the two previous contradictory identities and the tensions that they imply in his own personality? I am proposing a topographic model combining these three distances in order to locate education ethnography studies and education ethnographers' careers.
\end{abstract}

Keywords: distance; ethnography; education; epistemology; fieldwork; anthropology

The objective of this distance analysis is to offer a visual framework for education ethnographers, allowing them to understand the main forces present when studying educational actors. My research question is therefore: 'how to epistemologically analyze and synthesize three distances when doing an ethnographic fieldwork in the world of education?' I propose to develop a method in this document (previous studies in ethnography and specifically in education ethnography) leading to an epistemology: considerations about proper distances for education ethnographers. In 1998, Walford wrote about the 'flexibility of methods' (2) when doing education ethnography. My hypothesis is that all learning paths can be drawn in a three-dimensional (3D) space including this flexibility of methods.

I will proceed in three steps: (1) personal research curricula, (2) out of which emerges three notions of (measurable) distances and (3) that I aggregate in a single 3D model. The reason for starting with personal research curricula will appear at the end of this contribution: I will use the four studies presented by placing them in the 3D model. The second part, distinguishing three kinds of distances, is also based on my personal research curricula and takes into account ongoing scientific discussions. My personal additional claim is that each of these distances is measurable, partly with the notion of time.

The issue of distances (from fieldwork, from scientific community and from oneself) is of the utmost importance in the field of education ethnography since frontiers between ethnographers and people studied are not always well determined: the researcher can be

*Email: oliviermarty@yahoo.fr

(C) 2014 Taylor \& Francis 
indigenous and vice versa. An epistemology of distance, helping to find the right sociological and psychological positioning for the researcher is, therefore, most helpful in education ethnography.

\section{State-of-the-art}

The question on distances is fundamental in the field of ethnography. The history of ethnography as a scientific discipline is linked to colonialism and distant explorations of remote countries. For these ethnographic methods to be used in social sciences applied to education, particularly in reviews like Qualitative Inquiry or International Journal of Qualitative Studies in Education, it is important to systematise the discussions about the notion of distance.

Researchers from Ethnography and Education have been pioneering these scientific discussions: in 1985, M. Hammersley wrote an article untitled 'From Ethnography to Theory: A Program and Paradigm in the Sociology of Education' where he mentioned, 'There is a shortage of well-developed and systematically tested theory in sociology, and in the sociology of education in particular'. The model we develop in this article follows his work to fill in this gap. In 1983, M. Hammersley wrote with P. Atkinson (2) that ethnography was about 'reflecting' the reality. Our model is an abstract reflection of the dailies activities in the fieldwork. The mirroring of reality leads to the question of the distance between the mirror and the reality, the mirror and the observer, and last but not least, the potential cracks or the inner tensions. This last distance has been recently discussed by Sofia Marques da Silva (2004): the positioning of the researcher on the dimension of 'familiar-strangeness'. The literature on the topic is abundant, and I will be helped by Bourdieu (1984), Rabinow (2007), Walford (1987) and more recently Trowler (2012) when analysing each of the three distances. This epistemological reflection is based on the empirical data, mostly my own works in different fields that I will now present.

\section{From exotic studies to insider ethnography of higher education Personal research background}

I have been trained in field study methods at Ecole Normale Supérieure in Paris, France. I have completed short participatory observations: in North Guyana, in the Amazonian rainforest, where I studied the construction of canoes by an indigenous tribe at the Maroni River bank (Marty 2002a) under the supervision of Prof. Philippe Descola (Collège de France). My focus was on the activity of the workers in different work situations: chopping down the tree in the forest and then carving the trunk in the canoes harbour, next to the village. I also studied new economy and high tech start-ups operating in the field of numeric edition (Marty 2002b), through a Goffmanian participatory observation. I was closer to sociology of work, trying to describe the socialisation of a freshly hired employee and writing down the story of the organisation from inside.

After these researches, I enrolled in a French grande école to acquire management skills. I dedicated my final-year dissertation to the subject of ethnography within companies (Marty 2004). This French dissertation, available online ${ }^{1}$, is an introduction to this article since some of its epistemological considerations are still valid while studying higher education as an organisation (Trowler 2012: Doing Insider Research in Universities). The question of distance from the field is raised in this dissertation; one of the notions that I will be developing later in this contribution. 
In 2011, I defended a Ph.D. in ethics about bullfighting. This might seem to be exotic and distant, but it is not: I grew up in south-west of Europe, where I got involved in many amateur bullfighting activities. My research was mainly a compulsion of readings about bullfighting values and field data: participation to corridas and interviews.

I have been an employee of a higher education public institution (French distance education) for two years, while following post-doctoral education sciences studies in a laboratory of another institution (Cnam). I have been occupying the position of a manager/ engineer in distance education. It is within this context that I have been developing researches on distance education engineering since 2011.

\section{An ethnography study on distance education engineering}

Since 2011, I have written documents about distance education dedicated to education engineering and distance education management (Marty 2012, 2014). These were presented orally at conferences or seminars or are accepted for paper publication in a scientific review.

In these documents, I have presented distance education engineering as an activity (I am doing ethnography action research). I have been using a parallel empirical procedure to one of Hammersley's (for example, 1998), studying in the Open University. I have developed field descriptions about curricula conception in order to train students in computer and management skills. I have shown how these curricula were designed according to national requirements and students' background: a curriculum being a way to lead the students from their previous knowledge (their background) to the competencies necessary by-law to get the diploma as defined by the government. I also wrote about monetisation and privatisation of French distance education, whereas there is a trend of online open educational resources.

Another part of the description is about teachers' aggregation in order to deliver all the specialised skills to the students. Team building has been presented as based on individual complementary competencies. And when teachers are replaced by computerbased learning (that is to say an education software), I have described how education software are adjusted by the engineer in order to meet national diploma requirements.

However, the point here is not to present results but to develop epistemological considerations regarding the research process. I will therefore stress the difficulties I encountered and the solutions I opted for. I will attempt to summarise three kinds of epistemic considerations around the notion of distance: distance from fieldwork, distance from oneself and distance from the scientific community. In all cases, I will give an overview of the distance with the notion of time. I therefore take for granted the notion of continuity from insider to outsider as proposed by Justine Mercer in 2007 in The challenges of insider research in educational institutions: there is not a binary divide between insiders and outsiders when it comes to research about educational institutions, it is rather a continuity and a matter of degree.

\section{Building a model out of this experience: on distance analysis}

Thinking about the difficulties I encountered throughout this personal research curriculum, I can distinguish three kinds of distances that constitute a model. I will now present these three distances: from fieldwork, from the scientific community and from oneself. There is literature about each of these distances that I will mention at the beginning of each sub-chapter. However, my personal contribution will offer a systemic vision, with the notion of time. 


\section{Distance to fieldwork}

The first distance I want to stress is the cultural distance to fieldwork. It is a classical issue in anthropology that has recently been exposed around the notion of 'otherness' (Tsalach 2013) and feeling as a stranger in the field of adult education (Breen 2012). In a nutshell, how far is the ethnographer from the people he is studying? It is about social distance and acceptance of the researcher within the institution he is studying. I use the term 'distance' since, Hall (1990) has shown that this social and cultural distance is physically expressed and can be visualised: the more an ethnographer is socially distant to his fieldwork, the more physically distant he stands when interacting with the people he is studying.

In my enquiries, I went progressively from very exotic studies (a huge distance separated me from the Djuka indigenous) to more or less common distance in modern social sciences (new economy companies, south-west Europe bullfighters) to an endogenous study within a higher education institution (distance education engineering).

This decreasing distance entails a first methodological consideration: when the researcher is an apparent foreigner (the only European person with a notebook and a pen in a Djukas tribe speaking 'talkie-talkie'), he/she naturally declares his enquiry. This enquiry is not necessarily understood, but it is visible. However, if the researcher is among colleagues in a higher education organisation, with the same cultural background and conception of science, he/she is much less visible. One can therefore be tempted not to declare one's enquiry. This might be done in order to keep the observed from changing their habits to appear what they would like to be seen as. Furthermore, it prevents them from influencing the researcher's study (because they might be interested in science and have their own point of view and because they want to use this study as a communication tool, and so on). The first bias of insiders is therefore methodological: since one is invisible, one is tempted not to declare himself/herself and collect different data.

Being an insider researcher, doing an endogenous study, has another consequence dealing with the notion of visibility. As French researchers of previous generation have pointed it out (for example, Bourdieu 1984), when one is too close to his fieldwork, one may not see what is evident. A foreign ethnographer can see the 'big picture' since everything is strange to him. He will naturally notice the way people are dressed, their notion of time, of space ... since he is looking from far away, with a lot of distance. On the other side, an insider is so used to his own world, he looks at it from such a short distance, that he/she is blind to many features. Being an insider makes many dimensions of the field natural and invisible.

However, distance is not necessarily set once and for all. Indeed, as the research process progresses, the researcher tends to get closer to his field. Cultural distance is therefore reduced with time spent on the field. I approached the indigenous tribe, progressively understanding their language, their social codes, accepting their work rituals - thus getting closer and closer to them. On the other hand, if one studies his/her colleagues at work, one will have to try and take a step back to be more distant to one's habits. As a result, research work is progressive and distance is variable: one does not observe the same things at the beginning and at the end of the field - this is why writing down regularly helps to keep track of this change of focus.

How can one measure this distance to fieldwork? It is a difficult task, but there are a few criteria that allow the quantification of this distance: what is the previous experience of the researcher (is one's familial or personal background closer to the field studied? What were the previous field studies in his scientific career?). Another criterion is the 
time spent on field (and I will later use this unique indicator as an approximation since it has been discussed by Jeffrey and Troman 2004): the longer it is, the closer the researcher gets to his field.

One has to note that time is linked to a specific space: it is the amount of time spent on field (by opposition to the amount of time spent in scientific institutions). One has to add a distinction between the physical presence on field, on the one hand, and the social attitude towards the indigenous, on the other hand. Is the researcher thinking and behaving all the time as a scientist or is he part of the time socialising with indigenous and becoming himself part of them (without any research objective)? Is he considered by the indigenous as a scientist or another member of the community? Depending on their attitudes, the researcher will be tempted to be, though on fieldwork time and space, acting either as a scientist or as a member of the tribe. Time and space are not sufficient to measure distance to fieldwork and to scientific community: one has to take into account the very activity of the researcher, wherever he/she is.

Moreover, time shall not necessarily be seen as a pure quantitative linear progression like in physics: it is also qualitative and certain moments count twice since twice more elements are noted or major interviews are done. For example, executive committees in an education organisation can condense time. All of a sudden, the observer sees many things and gets closer to his/her fieldwork. Until this point, the researcher belongs to the field and then another problem arises: how to be distant from oneself when one is closer to being indigenous?

\section{Distance to scientific community}

Distance to the scientific community is symmetric to distance from fieldwork. Once the researcher has been accepted by the people he is studying, he/she gets more distant from the scientific community: his identity has shifted from a pure scientific ethnographer to partially indigenous. This is an old dilemma in the craft of ethnography: the ethnographer is divided by the time spent on field as an explorer (progressively becoming indigenous) and the time spent with the scientific community of armchair anthropologists exploiting his/her findings. And this is especially true in the field of education ethnography since the limits between science and practice of education are not very strict.

The problem can be compared to the one raised by Max Weber (2004) more than a century ago when comparing science and politics as a vocation. One has to choose between objective study of education (science) and educational action (politics). However, education ethnographers, when belonging to university or, more broadly, higher education, are also teachers and curriculum managers. The legal status mixes educational politics and science and makes the divide hard to sustain.

After a while, the scientist studying those and making politics of education is himself a bit of an action man: he has completed a participatory observation and his point of view and his identity is partly that of an actor. He is therefore more distant to the scientific community of 'armchair anthropologists', due to his proximity to the field.

A major difficulty lies in the distance the researcher has to adopt when presenting his work: he has to guess what the reader is supposed to know about the topic he is writing about. When writing about an education institution, it is sometimes delicate to present it: is it common sense for the reader? What is, in this case, the interest of a general description since the scientists are close to this institution and already know about it? On the other hand, a brief introduction to French education system and its history, within which the institution is embedded, is sometimes necessary: especially when presenting 
researches to an international audience. Thus, the researcher has to adjust the distance, zooming in or out in his/her presentations to have the proper focus relative to the reader or auditor.

The second issue is how to measure this distance to scientific community. The production of field data is an answer to the demand of a laboratory of education sciences. This demand is embedded within international trends of research. Therefore, when taking daily notes, when presenting them orally in a seminar or in a conference and when publishing an article or a book, the researcher expects to reach a scientific audience. Completing fieldwork in an education institution can give some credit to scientific productions since it is an academic position, rather close to scientific community. For example, the institution I studied in French distance education, possesses its own international scientific review.

Here lies a possibility in measuring distance from the audience. Indeed, answers to questions such as the following give a hint of the distance to the scientific community: has the institution studied a science laboratory? Does it have a scientific research review and is it well known and established within the science community (in the specific field the scientist is part of)? What are the disciplines taught by the institution studied and are education sciences included?

The time spent doing researches outside the field (daily readings, attending monthly seminars, regular notes and oral presentations and publishing scientific working papers and articles) is also a way to quantify this distance. Once again, time is not smooth since certain moments have greater value (fruitful discussions and appreciated contribution by the scientific community).

\section{Distance to oneself}

Distance to oneself is less debated in the field of education sciences. Rabinow (2007) wrote about 'the anthropologist, an outsider who is by definition external to his usual lifeworld'. I will develop this idea: distance to one's world is a factor of strangeness to oneself. Alban Bensa (1995) is an anthropologist who also considered this issue. Distance to oneself can be seen as a result of the two previous distances: divided between field and scientific identities, the education ethnographer can come across an identity crisis until the moment he overcomes these contradictory positions and integrates fully within his/her personality the schemes of the two communities. Distance to oneself is therefore a psychological issue, dealing with discomfort due to a double belonging: to the fieldwork community and the scientific community. A psychological approach to it can be found in Erikson's (1994) writings in terms of life cycles and personal development - though not directly applied to this specific case of education ethnography.

As mentioned earlier, I have been employed in higher education as a manager/ engineer, and I conduct reflexive researches since I belong to a laboratory of education sciences. These parallel activities can be difficult since I sometimes wonder if I am an actor or a spectator in my daily activities. I sometimes hesitate on the point of view that I should adopt. To quote P. Trowler (2012, empl. 592), the exercise is to 'render the normal strange' and sometimes it feels strange to be the researcher who is trying to do an auto-ethnography. To overcome this I divide the day in two parts: work time in my workspace for work activities; research at home. Thus, there is no confusion in my mind.

However, I notice that the more hierarchy there is between fieldwork and scientific activity, the less confusion there is in one's mind. Effects of distance to oneself are produced by inversion of hierarchy or when there is an equal effort on both activities 
(when I spend as much time working as writing for my researches). Distance to oneself is therefore quantifiable as well as the distance to the field. It is a combination of distance from fieldwork and distance from the science community. And distance from oneself increases when the two cultures (here science work and fieldwork) are highly separated.

A consequence regarding epistemology (cf. Marty 2004, last chapter) is that participating is at least as important as observing. Participating comes first, then observing (reflecting once back home) and finally writing down regularly not to forget. Instead of a participatory observation, it is rather observatory participation. This is important since the scientist will not see the same things: being part of the action, he can observe the actors' interests and strategies and can present his/her own strategy as an actor - as stressed by a scientific researcher in organisation sciences (Crozier 1981). What would be invisible to a mere spectator is accessible to the actor.

It is then about objectification of one's subjectivity: how can a global point of view about an institution be defended by an actor implicated in his/her everyday life? The researcher, as an actor, interacts with other members of the institution and therefore, participates in its daily construction. He/she is involved in the construction process through the different social interactions. The difficulty is then to extract oneself from these interactions, to take a step back (to take some distance), in order to become a spectator. Sentiments, emotions, must then be put aside in order to remain clear-minded and neutral in one's description (though sometimes critical when comparing to other institutions).

To sum up, participating actively and taking a step back daily, to reflect at home, can be seen in three ways:

- Two parallel activities, as I try to maintain them in my current position. I will try to show later that the two activities have to be hierarchised in order to be conducted in the long run.

- Divergent activities: when it comes to financing one's scientific research, a paid employee in education is a limitation due to legal constraints. Therefore, it is sometimes contradictory to be both a scientist and a worker in one's field.

- Convergent activities: a long-term field study at work allows the outsider to see inner strategies and details that are too precise for a more distant scientist. I will develop this option in the last part of the article and show the benefits of a longterm field study, including the active participation of the scientist on his/her field.

\section{Combining distances: a 3D model}

I described three kinds of distances out of a personal research curriculum: from fieldwork, from the scientific community and from oneself. Let us now combine the three distances in a trigonometric model, that is to say a triangle graph with distance metrics.

I have chosen the word 'analysis' because I looked into the different dimensions of the notion of distance, one by one. I now want to combine these distances in a single figure. In the following chart, the three dimensions represent the three distances. The triangle has to be seen in the same plan, without any 3D spatial effects: the three dimensions are projected on a 2D plan. Each distance can be measured on a scale going from 0 to 10 , and I have shown earlier that distance to fieldwork and distance to scientific community can be estimated through time spent on the field and doing scientific activities. Distance to oneself is a combination of the two others. 


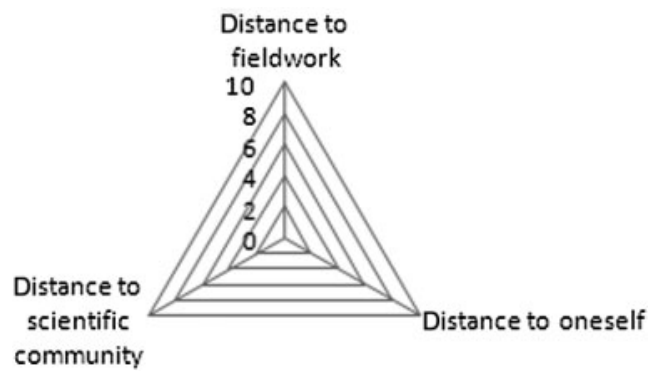

Figure 1. Combining distances: a 3D graph.

The importance of this measuring is not to have an exact positioning, but to get an overview of the distance profile of an education ethnographer. Is the researcher more of a field explorer? An 'armchair anthropologist' closely tied to a scientific community, controlling the paper outputs and the funding of researchers? Is his/her situation comfortable or does it entail many inner distances and tensions? What's more, positioning an education ethnographer can allow understanding his/her professional trajectory: some of them will, for example, start with a 'field profile' and turn into a 'scientific community profile' - or vice versa (Figure 1).

One can read the diagram with this legend:

- $D=$ distance to field

- $d=$ distance to scientific community

- $d / D=$ distance to oneself, a score near 1 is harder to maintain on the long run (because it means that the two activities are not clearly hierarchised, which entails identity hesitations). If distance to fieldwork $(D)$ is too small, then $d / D$ increases abruptly, and there is a high distance to oneself: the scientist has difficulties to maintain his/her main identity.

I will now place on this diagram the four ethnography studies I have presented earlier, in order to analyse them through the perspective of distance and determine the distance profile of each study. I will call this process the distance analysis.

Since it is not an orthogonal 3D space (with visual effect of depth), it is not possible to represent an ethnography study with a point having three coordinates. We will rather have a score on three dimensions projected on a plan and, therefore, draw a triangle (or profile) of each ethnography study.

In the first figure, I have compared the most exotic studies of Djuka tribe (I stayed only a few months in the jungle and I was very distant to the field) to the most indigenous in education (I have been involved in my fieldwork for three years, being an insider not distant at all). The distance to scientific community is smaller in the case of education, since I published and participated actively in the congresses, than in the case of Djuka, since I only published a single article. Therefore, distance from onself $(d / D)$ differs: it is higher in the case of education ethnography. Indeed, my identity is less clearly defined than in the case of the Djuka ethnography.

Considering the three dimensions for both studies, it appears that the triangle representing the research on distance education has a smaller surface than the one representing the research on Djuka tribe. I will show in the last part of this article that this is a better ethnographic position (Figure 2). 


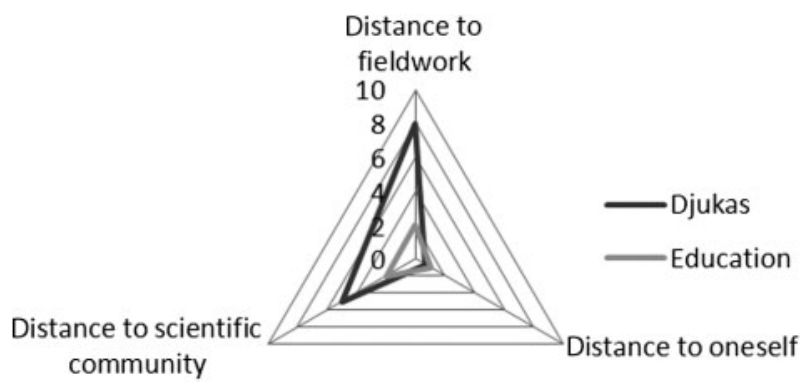

Figure 2. Distance analysis of ethnographic studies 2.

In the second figure, I compare the two other ethnographic studies mentioned: the Ph.D. about bullfighting and the four years research project about Start Up of the new economy. The two shapes are rather similar: distance to fieldwork is equal (I spent the same amount of time on field during both projects, being progressively admitted as a member of the communities throughout the years) and distance to scientific community is slightly smaller for Start-Up studies (there were more seminars in France considering this topic and I published more) than for Bullfighting. Therefore, distance to oneself was smaller for Start Ups than bullfighting (since I was clearly a scientist and not involved in new economy - though hired as a trainee in two institutions; Figure 3).

In this diagram, the two triangles are rather similar, the one drawing the distance analysis of Start-Up ethnography is slightly smaller than the one of bullfighting ethnography since I was closer to scientific community in the first case.

When comparing the triangles through their area (calculated with a trigonometric formula or simply looking at them), it appears that the smallest, the one minimising distances, is the triangle representing ethnography study of distance education. On the opposite, the short-term study on a very distant field is the biggest triangle. Indeed, I felt these distances doing my research, being much less comfortable in the jungle than in my education office - even though the question of distance to oneself would indicate an uncertainty in identity stronger in the case of education ethnography than in the case of jungle scientific fieldwork. My interpretation is that the smaller the area is, the more efficient the study is: the researcher is both near the fieldwork and the scientific community, ideally without an identity uncertainty due to equal distances.

Let us now develop, in the final part of this document, what would be the optimal shape of distance analysis's triangles. That is to say: what would be the optimal distance combination while doing an ethnography study in the field of education?

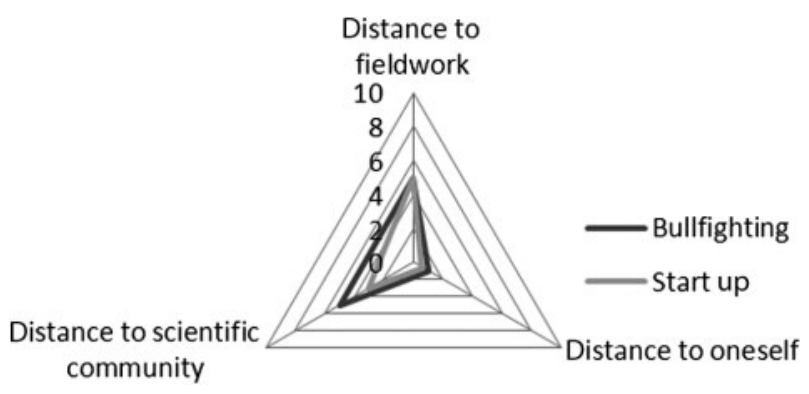

Figure 3. Distance analysis of ethnographic studies 3. 


\section{Conclusion}

\section{Minimising distances}

I would like to launch a discussion about the optimal position in a distance analysis: what are the best scorings in each dimension in order to conduct an education ethnography study?

I defend that a long-run enquiry on the same field (though occupying different positions in order to change from one point of view to the other) is a better way to know it in depth. Indeed, the scientist can see details invisible at first sight, including actors' strategies and evolution, group construction through interactions. Therefore, a small distance to the field would be preferable. This can be ideally completed by a full description of the approach: different focus of the institution, from a distant point of view to a close up. Therefore, the description is more complete and can be adapted to different audiences being at different cultural distances from fieldwork.

A small distance to scientific community is preferable in order to present (orally in seminar and congress or though written publications) one's findings and to benefit from critiques or comments in order to improve them. It is also a way of updating one's theoretical knowledge about the field and new scientific methods. Regular scientific activity allows to minimise this distance and to enhance the scientific production.

The question of distance to oneself is a major one. If both distance to fieldwork and distance to scientific community are small, there is a risk that the hierarchy between fieldwork activities and identity on one side, scientific activities and identity on the other side, would not be well defined. If the two distances are equal, distance to oneself is equal to one (if $\mathrm{d}=\mathrm{D}$ then $d / D=1$ ). It is a small distance, but a difficult one to maintain in the long run since there is a risk of changing careers and confusing activities. And if distance to fieldwork is too small, that is to say if $D<1$, then distance to oneself $(d / D)$ tends towards infinity: it increases abruptly. A distance to fieldwork too small is dangerous for the scientist since it leads to identity confusion.

Therefore, the best option would be a small distance to fieldwork (but not too small in order to avoid confusion) and an even smaller distance to scientific community. The scientist is well adapted to his fieldwork (small $D$ ) but is above all a scientist (even smaller $d$ ).

\section{Summary and perspective}

In conclusion, I propose this distance analysis as a tool to help any ethnographer involved in long-term scientific fieldwork in education. As I demonstrated, the measure of distances is rather qualitative since it is based on different indicators. Thereby, a representation of one's study can be drawn; it is represented by a triangular shape. Within this frame, my personal suggestion is to minimise all distances.

The objective of this distance analysis is to offer a visual framework for education ethnographers, allowing us to figure out what are the main forces present when studying educational actors. This model aims to help in finding the right social and psychic positioning for a study of higher education - which is neither the same for every study, nor constant all along an academic career. A further theme for reflection is how these epistemological considerations question the transition from ethnography to anthropology: can anthropologists take advantage of this ethnography episteme? 


\section{Note}

1. http://olivier.txt.voila.net/these/ethnographiedentreprise.htm.

\section{References}

Atkinson, P., and M. Hammersely. 1983. Ethnography, Principles in Practice. London and New York: Tavistock.

Bensa, A. 1995. "De la Relation Ethnographique. À la recherche de la juste distance [On Ethnographical Relationship. Looking for the Proper Distance]." Enquête 1, Éditions Parenthèses, Marseille, 131-140.

Bourdieu, P. 1984. Homo Academicus (Les éditions de Minuit, le sens commun).

Breen, M. 2012. "An 'Other' Perspective: Emancipation in Alterity?" Adult Learner: The Irish Journal of Adult and Community Education EJ991822, 115-124.

Crozier, M. 1981. Actors and Systems: The Politics of Collective Action. Chicago: University of Chicago Press.

Erikson, E. 1994. Identity and the Life Cycle. New York: Norton.

Hall, E. T. 1990. The Hidden Dimension. New York: Anchor Publisher.

Hammersley, M. 1985. "From Ethnography to Theory: A Programme and Paradigm in the Sociology of Education." Sociology 19 (2): 244-259. doi:10.1177/0038038585019002007.

Jeffrey, B., and G. Troman. 2004. "Time for Ethnography." British Educational Research Journal 30: 535-548. doi:10.1080/0141192042000237220.

Marques da Silva, S. 2004. "Doubts and Intrigues in Ethnographic Research." European Educational Research Journal 3 (3): 566-582.

Marty, O. 2002a. 'A partir de la construction d'une pirogue Djuka: milieu fermé versus milieu ouvert [Out of the Making of a Djuka Canoe: Open versus Closed Fields]'. ethnographiques.org, N 2. Accessed May 2014. http://www.ethnographiques.org/2002/Marty.

Marty, O. 2002b. 'La vie de Start Up. S'investir dans les entreprises innovantes [Start Up's Life: Investing Time and Money in Innovative Companies]', Gérer et comprendre, n 67. Accessed May 2014. http://www.annales.org/gc/2002/gc67-2002/marty004-015.pdf.

Marty, O. 2004. "Ethnography of Organizations." Final dissertation at Edhec grande école. Nice, France. Accessed May 2014. http://olivier.txt.voila.net/these/ethnographiedentreprise.htm.

Marty, O. 2012. Le projet $G$, une ingénierie de la formation [Project G, an Example of Training Engineering], oral presentation material available on the author's institutional research webpage: http://educations.voila.net.

Marty, O. 2014. "Monetization of French Distance Education." The International Review of Research in Open and Distance Learning, 15 (2). http://www.irrodl.org/index.php/irrodl/article/ view/1677/2831.

Mercer, J. 2007. "The Challenges of Insider Research in Educational Institutions: Wielding a Double-edged Sword and Resolving Delicate Dilemmas." Oxford Review of Education 33: 1-17. doi:10.1080/03054980601094651.

Rabinow, P. 2007. Reflections on Fieldwork in Morocco. Berkeley, CA: University of California Press.

Trowler, P. 2012. Doing Insider Research in Universities. Seattle, WA: Amazon Kindle Edition.

Tsalach, C. 2013. "Between Silence and Speech: Autoethnography as an Otherness-Resisting Practice." Qualitative Inquiry 19 (2): 71-80. doi:10.1177/1077800412462986.

Walford, G. 1987. "Introduction: The Research Process." In Doing Sociology of Education, edited by G. Walford, 1-15. London: Guildford Press.

Walford, G. 1998. "Research Accounts Count." In Doing Research about Education, edited by Geoffrey Walford, 1-11. London: Routledge.

Weber, M. 2004. The Vocation Lectures: Science as a Vocation, Politics as a Vocation. Indianapolis, IN: Hackett. 